\title{
Dexamethasone Implant (Ozurdex) in a Case with Unilateral Simultaneous Central Retinal Vein and Branch Retinal Artery Occlusion
}

\author{
Taylan Ozturk Omer Takes A. Osman Saatci \\ Department of Ophthalmology, Dokuz Eylul University, Izmir, Turkey
}

\section{Key Words}

Branch retinal artery occlusion - Central retinal vein occlusion $\cdot$ Combined retinal artery and vein occlusion $\cdot$ Dexamethasone intravitreal implant $\cdot$ Ozurdex

\begin{abstract}
Simultaneous branch retinal artery and vein occlusion is a rare condition that may cause severe visual loss, and its treatment is often unrewarding. Herein, we report a case with simultaneous central retinal vein and branch retinal artery occlusion; it was successfully treated with a single dexamethasone intravitreal implant. The affected eye attained a visual acuity level of 20/25 from the visual acuity of hand motions at presentation with a residual, but relatively diminished, altitudinal scotoma during a follow-up period of 6 months.
\end{abstract}

(C) 2015 S. Karger AG, Basel

\section{Introduction}

Combined retinal artery and vein occlusion is a rare condition, and 3 different variants have been reported: central retinal vein occlusion (CRVO) with central retinal artery occlusion (CRAO), CRVO with branch retinal artery occlusion (BRAO), and CRVO with cilioretinal artery occlusion. The most frequent type is CRVO with cilioretinal artery occlusion that is caused by a sudden rise in intraluminal pressure in the retinal capillary bed [1,2]. Both arterial and venous disorders of the retina may be triggered by the same underlying systemic pathologies, such as hypertension, diabetes, systemic vasculitis, coagulopathies, homocysteinemia, and rheumatologic diseases [1-3]. Macular edema is the leading cause of visual mor- 
Ozturk et al.: Dexamethasone Implant (Ozurdex) in a Case with Unilateral

Simultaneous Central Retinal Vein and Branch Retinal Artery Occlusion

bidity in eyes with retinal vein occlusion, and the efficacy of dexamethasone intravitreal implants in retinal vein occlusion-related macular edema has been well known [4-7]. Herein, we report a case with simultaneous CRVO and BRAO that was successfully treated with a single dexamethasone intravitreal implant.

\section{Case Report}

We examined a 30-year-old male with a sudden, painless visual loss in his right eye that lasted for $3 \mathrm{~h}$. Nine years ago, he had been treated with scatter laser photocoagulation for an ischemic type of upper branch retinal vein occlusion (BRVO) in the left eye. At that time, he was diagnosed with homocysteinemia with the homozygous C677T mutation in the methylenetetrahydrofolate reductase gene. After a detailed systemic workup, he was put on warfarin sodium. On examination, his best-corrected visual acuity (BCVA) was hand motions in the right eye and 20/30 in the left eye. A slit-lamp examination was unremarkable in each eye. The intraocular pressure was $15 \mathrm{~mm} \mathrm{Hg}$ in both eyes. Dilated fundoscopy revealed tortuous and dilated retinal veins with $360^{\circ}$ scattered retinal hemorrhages as well as a clearly demarcated pale retina in the distribution of the upper temporal artery in the right eye and scattered laser spots with macular retinal pigment epithelium changes in the left eye (fig. 1). Our fundus autofluorescent image clearly depicted the extent of the infarcted area (fig. 2a), and fluorescein angiography demonstrated that the peripheral retina was well perfused in the right eye (fig. 2b). Optic coherence tomography (OCT) showed the presence of subretinal fluid and the ganglion cell layer infarct in the right eye (fig. 2c). The diagnosis was simultaneous CRVO and upper BRAO in the right eye. After a prompt digital ocular massage and a $20 \%$ mannitol infusion, an anterior chamber paracentesis was immediately performed. However, no visual improvement was noted following the procedure. Two weeks later, a dexamethasone intravitreal implant (Ozurdex, Allergan Inc., Irvine, Calif., USA) was injected into the right vitreous cavity to at least alleviate the CRVO-related concomitant macular edema, as the patient still had a visual acuity of hand motions in the right eye. Visual acuity gradually improved in the following weeks with a remarkable decrease in the central macular thickness, and no postoperative injection-related complication was observed. Six months after the operation, the retinal anatomy appeared to be dramatically improving (fig. 3a, b), and his BCVA was found to be 20/25. His visual field defect contracted with time in the right eye (fig. $4 a, b)$.

\section{Discussion}

It is well known that intravitreal steroid administration has a beneficial effect on the retinal inflammation and it also lessens the macular edema [4-7]. The efficacy and safety of dexamethasone intravitreal implants in patients with either CRVO or BRVO has been well defined in prospective multicenter studies [5-7]. Sporadic case reports were published before about the efficacy of intravitreal triamcinolone acetonide or vascular endothelial growth factor inhibitors in patients with combined retinal artery and vein occlusion [8-10]. Schwartz et al. [8] reported a 50-year-old woman who developed bilateral CRVO and CRAO related to secondary thrombotic thrombocytopenic purpura. Only her right eye was treated with $4 \mathrm{mg}$ of intravitreal triamcinolone acetonide 2 weeks after her episode. A week later, intravitreal $1.25 \mathrm{mg}$ bevacizumab was administered to each eye to fight the springing rubeosis in addition to the panretinal photocoagulation. Lima et al. [9] reported a 38-year-old man 
Ozturk et al.: Dexamethasone Implant (Ozurdex) in a Case with Unilatera

Simultaneous Central Retinal Vein and Branch Retinal Artery Occlusion

with a 2-hour history of acute unilateral visual loss due to combined papillophlebitis and CRAO. The patient received a combination of intravitreal triamcinolone $(4 \mathrm{mg})$ and bevacizumab $(1.25 \mathrm{mg})$ injections in the affected eye immediately following the anterior chamber paracentesis. He also received a carbogen inhalation therapy, intravenous Solu-Medrol, oral pentoxifylline as well as aspirin. After a month, his BCVA improved to 20/30 from the initial visual acuity level of counting fingers at 2 inches. Katsimpris et al. [10] administered a single intravitreal ranibizumab injection for a unilateral combined cilioretinal artery and CRVO in a 38-year-old man and a 42-year-old woman. In both cases, their visual acuity recovered significantly and the macular edema regressed within days.

To the best of our knowledge, this is the first case report with combined retinal artery and vein occlusion that was treated with a single dexamethasone implant. The visual acuity of the treated eye improved to $20 / 25$ from a presenting visual acuity of hand motions with a residual scotoma during the follow-up period of 6 months. When natural history data are considered, presenting and final visual acuity is relatively good in eyes with isolated BRAO [11]. In a group of 61 eyes with BRAO examined within 7 days of the episode, only $26 \%$ of the eyes had $20 / 50$ or worse initial visual acuity, and visual acuity improved in $79 \%$ of these eyes. Natural history data for nonischemic CRVO were also evaluated by Hayreh et al. [12]. Visual acuity was $20 / 100$ or better in $78 \%$ of eyes with nonischemic CRVO first seen within 3 months of onset, and the visual acuity improved in 59\% of the eyes with an initial visual acuity of $20 / 70$ or worse after the resolution of macular edema. It was likely that dexamethasone implants might have positively contributed to the anatomic and visual outcomes in the present case mainly by alleviating CRVO-related macular edema.

\section{References}

1 Hayreh SS, Fraterrigo L, Jonas J: Central retinal vein occlusion associated with cilioretinal artery occlusion. Retina 2008;28:581-594.

-2 Okamoto N, Matsumoto C, Shimomura Y: Sequential occlusion of the branch retinal artery and branch retinal vein in a patient with hypertension: an interventional case report. Clin Ophthalmol 2014;8:21212123.

-3 Schmidt D: Comorbidities in combined retinal artery and vein occlusions. Eur J Med Res 2013;18:27.

-4 Lambiase A, Abdolrahimzadeh S, Recupero SM: An update on intravitreal implants in use for eye disorders. Drugs Today (Barc) 2014;50:239-249.

-5 Haller JA, Bandello F, Belfort R Jr, et al: Dexamethasone intravitreal implant in patients with macular edema related to branch or central retinal vein occlusion twelve-month study results. Ophthalmology 2011;118:2453-2460.

-6 Bezatis A, Spital G, Höhn F, et al: Functional and anatomical results after a single intravitreal Ozurdex injection in retinal vein occlusion: a 6-month follow-up - the SOLO study. Acta Ophthalmol 2013;91:e340e347.

7 Coscas G, Augustin A, Bandello F, et al: Retreatment with Ozurdex for macular edema secondary to retinal vein occlusion. Eur J Ophthalmol 2014;24:1-9.

-8 Schwartz SG, Hickey M, Puliafito CA: Bilateral CRAO and CRVO from thrombotic thrombocytopenic purpura: OCT findings and treatment with triamcinolone acetonide and bevacizumab. Ophthalmic Surg Lasers Imaging 2006;37:420-422.

9 Lima VC, Prata TS, Landa G, et al: Intravitreal triamcinolone and bevacizumab therapy for combined papillophlebitis and central retinal artery occlusion. Retin Cases Brief Rep 2010;4:125-128.

-10 Katsimpris JM, Theoulakis PE, Lepidas J, et al: Combined cilioretinal artery and central retinal vein occlusion treated with a single injection of ranibizumab. Klin Monbl Augenheilkd 2011;228:391-394.

-11 Hayreh SS, Podhajsky PA, Zimmerman MB: Branch retinal artery occlusion: natural history of visual outcome. Ophthalmology 2009;116:1188-1194.

12 Hayreh SS, Podhajsky PA, Zimmerman MB: Natural history of visual outcome in central retinal vein occlusion. Ophthalmology 2011;118:119-133. 
Case Reports in

Ophthalmology

\begin{tabular}{l|l}
\hline \multicolumn{2}{l|}{ Case Rep Ophthalmol 2015;6:76-81 } \\
\hline DOI: $10.1159 / 000377668$ & $\begin{array}{l}\text { C } 2015 \text { S. Karger AG, Basel } \\
\text { www.karger.com/cop }\end{array}$ \\
\hline
\end{tabular}

Ozturk et al.: Dexamethasone Implant (Ozurdex) in a Case with Unilateral

Simultaneous Central Retinal Vein and Branch Retinal Artery Occlusion
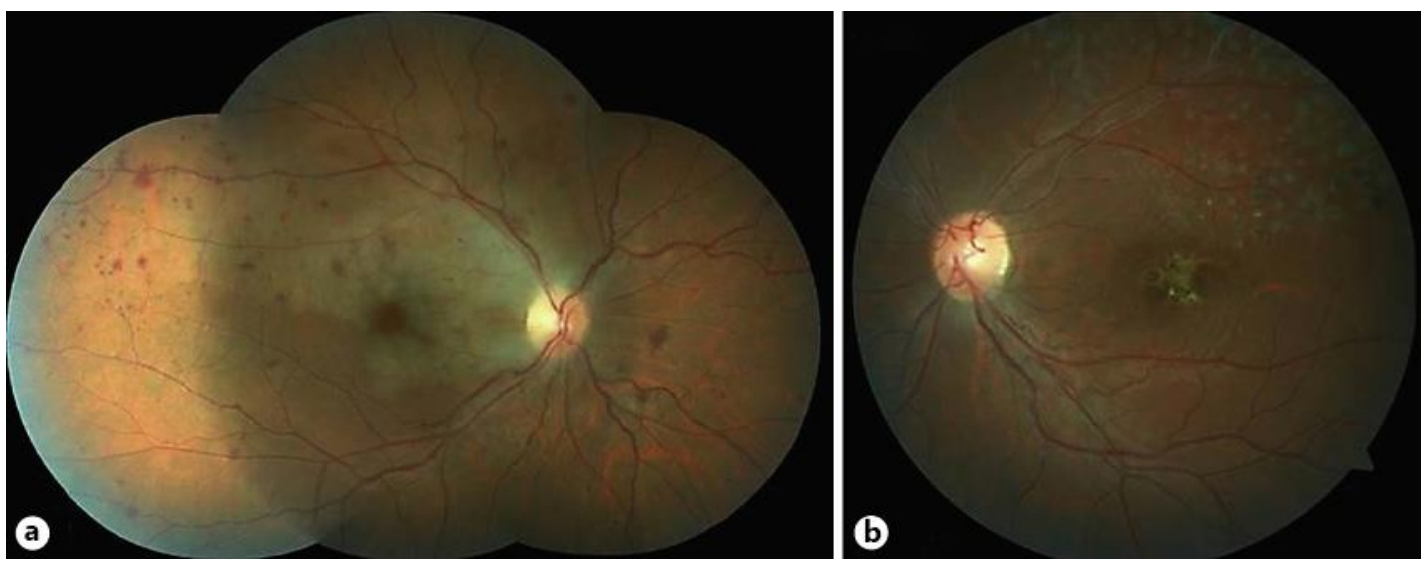

Fig. 1. Color fundus photographs of the right (a) and the left eye (b) at the time of presentation.
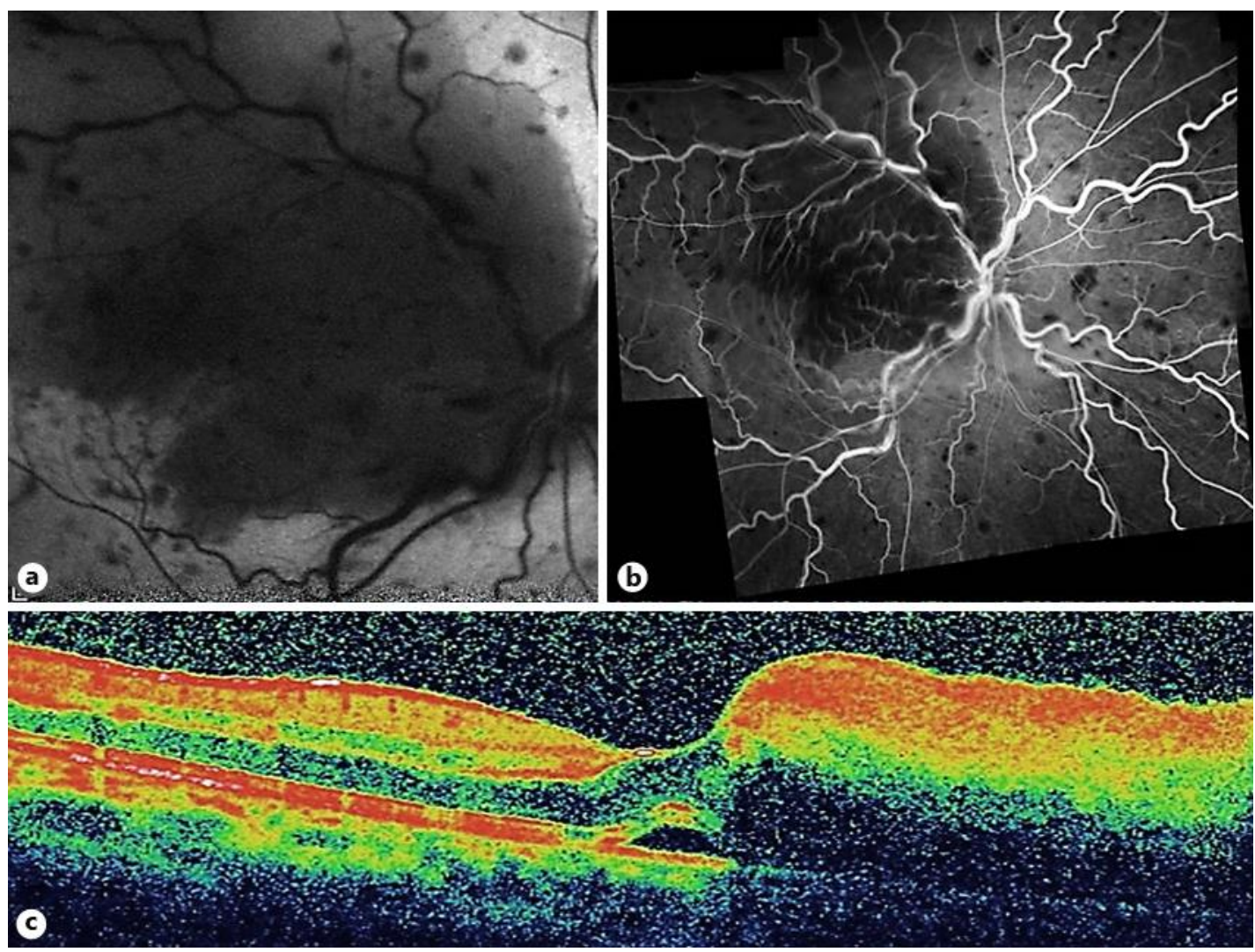

Fig. 2. Autofluorescence (a) and fluorescein angiography (b) images of the affected eye with the segmental infarct related to the occlusion of the upper temporal branch of the retinal artery. Subretinal fluid, increased macular thickness and increased reflectivity of the ganglion cell layer corresponding to the infarcted area were notable on OCT (c). 
Case Reports in

Ophthalmology

\begin{tabular}{l|l}
\hline \multicolumn{2}{l|}{ Case Rep Ophthalmol 2015;6:76-81 } \\
\hline DOI: $10.1159 / 000377668$ & $\begin{array}{l}\text { C } 2015 \text { S. Karger AG, Basel } \\
\text { www.karger.com/cop }\end{array}$ \\
\hline
\end{tabular}

Ozturk et al.: Dexamethasone Implant (Ozurdex) in a Case with Unilateral Simultaneous Central Retinal Vein and Branch Retinal Artery Occlusion

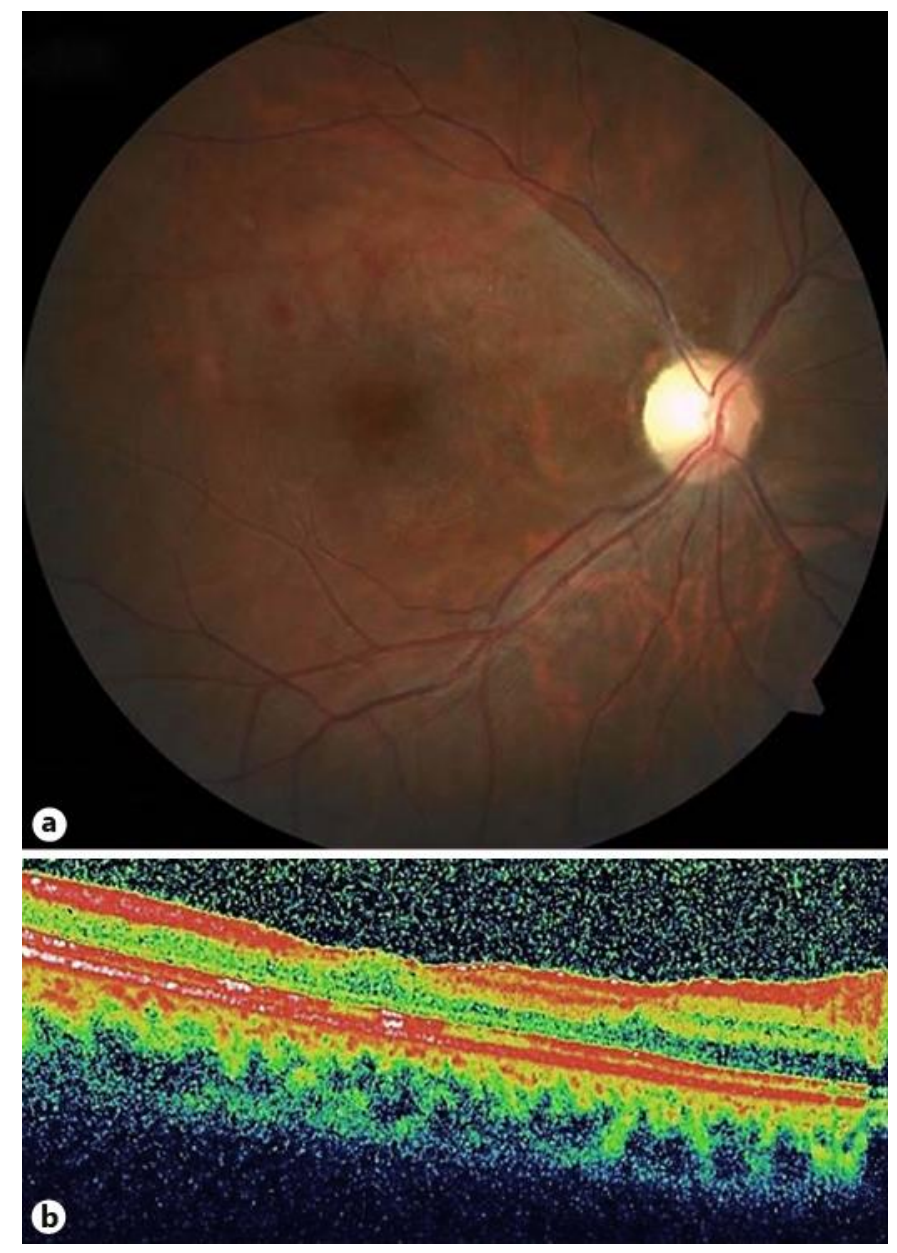

Fig. 3. Color fundus photograph (a) and OCT scan (b) of the right eye 6 months after the injection. 


\section{Case Reports in \\ Ophthalmology}

\begin{tabular}{l|l}
\hline \multicolumn{2}{l}{ Case Rep Ophthalmol 2015;6:76-81 } \\
\hline DOI: 10.1159/000377668 & $\begin{array}{l}\text { ○ 2015 S. Karger AG, Basel } \\
\text { www.karger.com/cop }\end{array}$ \\
\hline
\end{tabular}

Ozturk et al.: Dexamethasone Implant (Ozurdex) in a Case with Unilateral

Simultaneous Central Retinal Vein and Branch Retinal Artery Occlusion
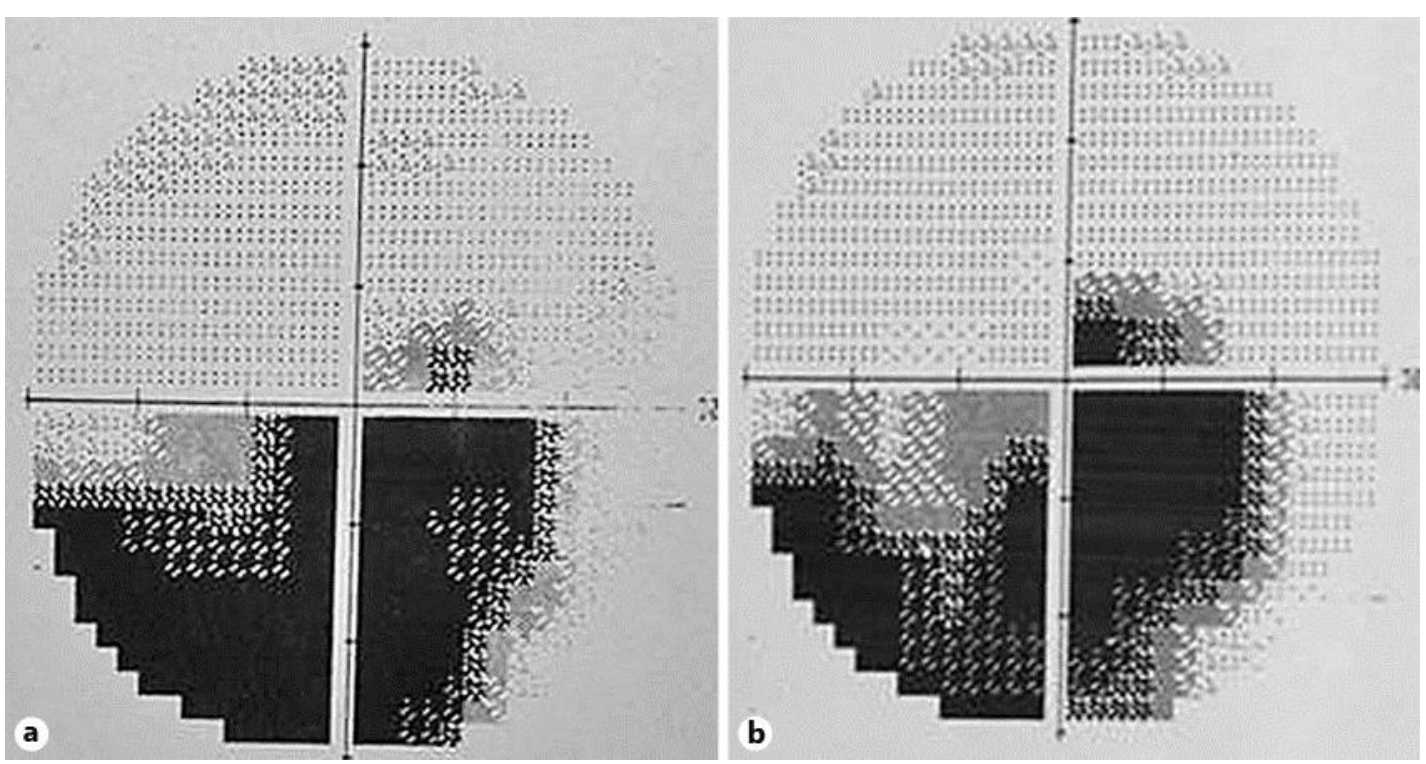

Fig. 4. Visual field defects corresponding to the infarcted retinal sector at the third (a) and sixth (b) postoperative months. 